\title{
Comparison of Isobaric Levobupivacaine with Hyperbaric Bupivacaine in spinal anesthesia in patients undergoing Lower Abdominal Surgeries
}

\author{
Authors \\ Ramya Metta ${ }^{1}$, Kalyan Chakravarthy $\mathbf{P}^{2}$, Hemnath Babu $\mathbf{K}^{3}$, \\ Jyotsna Rani $\mathbf{P}^{\mathbf{4}}$, Arun $\mathbf{P}^{\mathbf{5}}$ \\ ${ }^{1}$ Post graduate, Department of Anaesthiology, GEMS \\ ${ }^{2}$ Professor, Department of Anaesthiology, GEMS \\ ${ }^{3}$ Associate professor, Department of Anaesthiology, GEMS \\ ${ }^{4,5}$ Postgraduate, GEMS
}

\begin{abstract}
Background: Levobupivacaine which is an S (-) enantiomer of bupivacaine with properties of low cardioneurotoxicity. Usage of isobaric levobupivacaine in spinal anesthesia had started recently.

Objective: The study aimed to compare isobaric levobupivacaine and hyperbaric bupivacaine among patients undergoing lower abdominal surgeries regarding efficacy and safety.

Materials and Methods: 60 healthy patients were divided into two groups of 30 each. They received $3 \mathrm{ml}$ $0.5 \%$ (15mg) of hyperbaric bupivacaine in group B and $3 \mathrm{ml} 0.5 \%(15 \mathrm{mg})$ of isobaric levobupivacaine in group L intrathecally. Both groups were compared regarding the onset of sensory-motor block, hemodynamic profile, adverse effects and duration of analgesia.

Results: The onset of sensory block (time to T10) was significantly faster in group B $(7.67 \pm 1.49)$ compared to group L (10.00 \pm 1.05$), p<0.001$. All patients achieved Bromage score of 3 and the evolution of motor block was faster and lasted longer in group B $(6.73 \pm 1.23)$ compared to group L $(8.8 \pm 1.45)$ with a p-value of $<0.0001$. Among both the groups, incidence of hypotension and bradycardia was significantly more in group B compared to group L. Duration of analgesia were significantly longer in group B than group $L, p$ $<0.0001$ while motor blockade was comparable, $p=0.21$.

Conclusion: Isobaric levobupivacaine offering an effective sensory-motor blockade with stable hemodynamic profile and decreased central nervous system and cardiovascular toxicity is a better alternative to hyperbaric bupivacaine in spinal anesthesia for lower abdominal surgeries.
\end{abstract}

Keywords: Intrathecal, bupivacaine, levobupivacaine, lower abdominal surgery, spinal anesthesia.

\section{Introduction}

Spinal anaesthesia is an easy, inexpensive and mostly preferable technique for lower abdominal surgery, as it provides a rapid onset of sensory and motor block with, attenuation of the stress response and decreases thromboembolic episodes. Even though Bupivacaine is the most commonly used local anaesthetic agent in spinal anaesthesia, there had been cases reported where unintended intravascular injection of bupivacaine during attempted neuraxial anaesthesia resulted in sudden cardiac arrest refractory to resuscitation. ${ }^{[1],[2]}$ Amide local anaesthetics have a chiral centre and exists as Levo S (-) and dextro R (+) stereoisomer's. Among the isomers, dextro form was found to be more toxic. ${ }^{[3]}$ 
Ropivacaine was the first levo enantiomer introduced in the early 1990s, had higher safety profile $^{[4]}$ than bupivacaine, but was lesser potent ${ }^{[5]}$ and could not become a better alternative to bupivacaine. Recently introduced another levo isomer is levobupivacaine, which has drawn interest as it is almost equal to bupivacaine regarding potency ${ }^{[6]}$ with a better safety profile ${ }^{[7]}$

Hyperbaric local anesthetic preparations are preferred nowadays in spinal anesthesia because they produce effective sensory and motor block, with early-onset compared to plain solution as observed with bupivacaine, ${ }^{[8]}$ ropivacaine ${ }^{[9]}$ and levobupivacaine ${ }^{[10]}$ As commercial preparations of hyperbaric levobupivacaine are not available in India, the addition of glucose and making it hyperbaric in every case in cumbersome and safety is also being questioned.

Hyperbaric bupivacaine in spinal anesthesia is still a gold standard in our country; however, there is the scarcity of data which show comparable efficacy between intrathecal isobaric levobupivacaine and hyperbaric bupivacaine ${ }^{\cdot[11],[12],[13],[14]}$

Therefore we designed the present study to compare sensory-motor block characteristics, hemodynamic profile and side effects with equivalent doses (15mg) of isobaric levobupivacaine and hyperbaric bupivacaine in spinal anesthesia among patients undergoing lower abdominal surgery. Our ultimate aim is if isobaric levobupivacaine is found to be clinically effective, it becomes a better alternative compared to hyperbaric bupivacaine in spinal anesthesia, because of it of its lesser toxic effects on heart and CNS. ${ }^{[15]}$

\section{Material and Methods}

After institutional ethical committee clearance and informed written consent had been taken from patients, the present study was carried out in the Department of Anesthesia, Great eastern medical school \& hospital, Srikakulam.

Study Design: A prospective, randomized, doubleblind, comparative study.

Study Population: Sixty patients of ASA I, II of either sex or ages between 18-65 yrs scheduled for elective lower abdominal surgery under spinal anaesthesia were enrolled in the study. A thorough pre-anaesthetic evaluation was carried on with necessary investigations.

Exclusion Criteria were patients with coagulation disorders, on anticoagulants, patient refusal, spinal deformity, allergic to amide local anaesthetics, morbid obesity (body mass index $>29 \mathrm{~kg} / \mathrm{m} 2$ ), Systemic illness, musculoskeletal and psychiatric diseases that could make our technique difficult

Randomization and group allocation: Sixty patients were randomly allocated into two groups of 30 each using sealed envelope method, depending on the drug regime used for spinal anaesthesia as follows:

Group B: received $3 \mathrm{ml}$ of $0.5 \%$ hyperbaric bupivacaine (15 mg).

Group L: received $3 \mathrm{ml}$ of $0.5 \%$ plain (isobaric) levobupivacaine (15 mg).

Spinal Anaesthesia Technique: Following arrival in the pre-anaesthetic room, intravenous access was secured and preloaded with $500 \mathrm{ml}$ Ringer lactate and was briefed about the methods used for sensory and motor assessments. Standard monitoring were applied including containing non-invasive blood pressure (NIBP), electrocardiography (ECG), heart rate $(\mathrm{HR})$ and pulse oximetry $(\mathrm{SpO} 2)$. Baseline values were noted. With the patients in the sitting position, and under strict aseptic conditions, a lumbar puncture was performed in the midline at L3-L4 interspace, using Quincke 25G spinal needle. Correct needle placement was identified by free cerebrospinal fluid (CSF) flow. The study drug was given into subarachnoid space according to group allocation, and the patient was placed supine.

\section{Data Recording}

Sensory block was measured by the pinprick method $^{[13]}$ at 2, 4, 6, 8, 10, 12 and 15 minutes after drug injection to assess the time taken to reach T10 level, peak block height. Absence of sensation to pinprick was considered as the sensory block. The onset of adequate sensory block was defined as the achievement of sensory block to T10 dermatome. 
Motor block was assessed based on modified Bromage scale as follows. ${ }^{[13]}$

$0=$ no paralysis, able to flex hips, knees, ankles;

$1=$ able to move knees but unable to raise extended legs

2=able to flex ankles, unable to flex knees;

$3=$ not able to move any part of the lower limb.

Motor block was also assessed at 2, 4, 6, 8, 10, 12 and 15 minutes after intra thecal injection.

Onset time of motor block (time to reach maximum Bromage score) was also recorded. Complete motor block was defined as interval between intra thecal administration and to a Bromage score of 3 .

Intraoperative heart rate (HR) and non - invasive blood pressure (NIBP) was recorded initially at 2minute interval for the first $10 \mathrm{~min}$, after that every 5 minutes till the end of surgery. Intraoperative fluid and blood transfusion were given as per losses and maintenance required.

Hypotension was defined as a decrease in the systolic blood pressure (SBP) of less than 100 $\mathrm{mmHg}$ and was treated with an injection of $6 \mathrm{mg}$ Ephedrine IV and fluids. Bradycardia was defined as fall in HR less than 50 beats per min and was treated with atropine $0.6 \mathrm{mg}$ IV bolus.

Incidence of intraoperative hypotension, bradycardia, nausea, vomiting, or other side effects were noted and treated accordingly. Duration of surgery was defined as the time from the start of surgery up to the last suture.

In post-anaesthesia care unit, for recovery characteristics, sensory and motor block were checked every 30 minutes till sensory regression to L1 and Bromage score returns to zero. Vital parameters (HR, NIBP) were also noted at the same intervals.

Duration of analgesia was defined as time of the first complaint of postoperative pain and rescue analgesia in the form of Tramadol $100 \mathrm{mg}$ IV was given as per institutional protocol.

\section{Statistical Analysis}

Quantitative data were presented as mean and standard deviation, and analyzed by using Student $\mathrm{t}$ test. Qualitative data were presented as number (proportion or \%). $\quad \mathrm{p}<0.05$ was considered statistically significant.

\section{Results}

Both groups were comparable regarding age, sex, ASA grade, duration of surgery and preoperative vital parameters.

\begin{tabular}{|l|c|c|c|}
\hline Variables & Group B & Group L & P value \\
\hline Age(in years) & $41.30 \pm 11.6$ & $42.86 \pm 19.8$ & 0.7 \\
\hline Sex (female) & $19(63.3 \%)$ & $18(60 \%)$ & 0.7 \\
\hline & & & \\
\hline ASA grade I & $11(37.3 \%)$ & $12(40 \%)$ & \\
\hline II & $15(50 \%)$ & $18(60 \%)$ & 0.7 \\
\hline
\end{tabular}

Block Characteristics: Sensory onset was significantly faster with hyperbaric bupivacaine as compared to isobaric levobupivacaine, as shown by difference in time to onset to T10 $(6.00 \pm 1.05 \mathrm{~min}$ in group $\mathrm{B}, 9.07 \pm 1.01 \mathrm{~min}$ in group $\mathrm{L}$ with a $\mathrm{p}$-value of $<0.001$.

\begin{tabular}{|l|c|c|c|}
\hline Variables & Group B & Group L & P value \\
\hline $\begin{array}{l}\text { onset of sensory } \\
\text { block(mins) }\end{array}$ & $6.00 \pm 1.05$ & $9.17 \pm 1.01$ & $<0.001$ \\
\hline $\begin{array}{l}\text { Time of complete } \\
\text { motor blockade } \\
\text { (mins) }\end{array}$ & $6.73 \pm 1.23$ & $8.8 \pm 1.45$ & $<0.0001$ \\
\hline $\begin{array}{l}\text { Duration of } \\
\text { analgesia (mins) }\end{array}$ & $217 \pm 35$ & $188 \pm 32$ & 0.0014 \\
\hline $\begin{array}{l}\text { Duration of } \\
\text { motor blockade } \\
\text { (mins) }\end{array}$ & $216 \pm 30$ & $205 \pm 37$ & 0.21 \\
\hline
\end{tabular}

All patients of both groups achieved maximum Bromage score of 3 , signifying complete motor block. Motor onset in terms of time to achieve maximum Bromage of 3 was significantly faster with hyperbaric bupivacaine $(6.73 \pm 1.23 \mathrm{~min})$ as compared to isobaric levobupivacaine $(8.8 \pm 1.45$ $\min ), \mathrm{p}<0.001$.

Duration of analgesia was significantly longer in group $\mathrm{B}(217 \pm 35 \mathrm{~min})$ as compared to group $\mathrm{L}$ (188 $\pm 32 \mathrm{~min}), \mathrm{P}=0.0014$

Duration motor block was also longer in group B (216 $\pm 37 \mathrm{~min})$ as compared to group L (205 $\pm 35 \mathrm{~min})$ however it could not reach statistical significance, $\mathrm{p}$ $=0.21$. 
Hemodynamic Profile: There was no significant difference in mean value of pulse rate systolic BP and diastolic BP in two groups throughout the study period. Only adverse effect observed during study were hypotension [30 \% $(n=9)$ in group B, 6.67\% $(n=2)$ in group L] and bradycardia [10 \% $(n=3)$ in group B] which too occurred as a single episode and could easily be treated with a single dose of Ephedrine $(6 \mathrm{mg})$ and atropine $(0.6 \mathrm{mg})$ respectively.

\begin{tabular}{|l|c|c|}
\hline Side effects & Group B & Group L \\
\hline Hypotension & $9(30 \%)$ & $2(6.67 \%)$ \\
\hline Bradycardia & $3(10 \%)$ & 0 \\
\hline
\end{tabular}

\section{Discussion}

Present study showed that intrathecal administration of $15 \mathrm{mg}$ isobaric levobupivacaine was well tolerated and provided effective spinal anesthesia for lower abdominal surgery.

We observed in our study that as compared to equivalent doses of hyperbaric bupivacaine, spinal anaesthesia with isobaric levobupivacaine had slower onset of sensory-motor blockade (approximately $3 \mathrm{~min}$ delay) and shorter block duration (approximately $30 \mathrm{~min}$ difference). Hemodynamic stability was more with isobaric levobupivacaine as showed by high incidence of hypotension (30\% in group B versus $6.6 \%$ in group L) and bradycardia with hyperbaric bupivacaine (10\% in group B versus $0 \%$ in group L).

Similar to our study Vanna et al ${ }^{[13]}$ compared $2.5 \mathrm{ml}$ of hyperbaric bupivacaine $0.5 \%$ with $2.5 \mathrm{ml}$ of isobaric levobupivacaine $0.5 \%$ in spinal anesthesia for TURP surgeries. Onset to T10 was faster with hyperbaric bupivacaine $(7.3 \pm 3.6 \mathrm{~min})$ as compared to isobaric levobupivacaine $(10.0 \pm 4.3 \mathrm{~min})$, and it was not statistically significant. $\mathrm{p}=0.22$. Demarzio $^{[11]}$ et al and Gulen et al ${ }^{[12]}$ also reported faster onset, higher peak sensory level and longer duration of block with hyperbaric bupivacaine as compared to isobaric levobupivacaine in cesarean. Higher peak sensory level and faster onset with hyperbaric bupivacaine as compared to isobaric levobupivacaine is due to two factors- bariciy and structural difference of two agents.
On contrary to the study done by Helmi et al ${ }^{[16]}$ comparing isobaric versus hyperbaric bupivacaine (4ml) it was found that isobaric bupivacaine produced more rapid onset [group I $(4.8 \pm 2.2 \mathrm{~min})$ versus group B $(7.5 \pm 2.2 \mathrm{~min})]$ and higher level of blockage T6(4-10) in group I versus T8 (T4-10) in group B]. Several reports have shown that isobaric bupivacaine spread unexpectedly cephalad, even after a reasonable time is allowed for fixation, thus causing late complication of hypotension and bradycardia due to high block. ${ }^{[17],[18]}$ It was explained that all plain anesthetic solutions are actually hypobaric in C.S.F, resulting in excessively high spread. ${ }^{[19]}$ In contrast, isobaric levobupivacaine was found different in this aspect, its block levels were distributed to a narrow range and did not spread to higher levels as observed in various

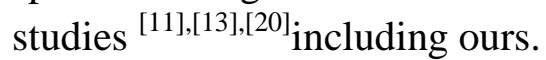

Gori et $\mathrm{al}^{[20]}$ described that specific gravity of isobaric levobupivacaine is very close to C.S.F, it acts indifferently to gravitational forces, both immediately after injection and later on, therefore, intrathecal isobaric levobupivacaine does not spread unexpectedly high and levels of sensory block are unaffected by change in patient position. This might be advantage over plain bupivacaine which tends to spread unexpectedly high.

Lacasse et $\mathrm{al}^{[21]}$ demonstrated that $\mathrm{S}$ enantiomers levobupivacaine is $13 \%$ less potent than bupivacaine. Camorica et $\mathrm{al}^{[22],[23]}$ reported that analgesic potency ratio of levobupivacaine/ bupivacaine is $0.81(95 \% \text { C.1 } 0.9-0.94)^{[31]}$ and motor block potency ratio is 0.71 (95\% C.1 $0.51-$ $0.98)^{[32]}$ If levobupivacaine and bupivacaine are compared in spinal anesthesia using same baricity solution then effect of potency difference can be better observed clinically.

Vellosillo et al (2014) ${ }^{[24]}$ found out that sensory onset time was significantly shorter for isobaric bupivacaine $1.5(1-10 \mathrm{~min})$ when compared with isobaric levobupivacaine $3(1-2 \mathrm{~min}), \mathrm{p}=0.018$. Fattorini et al (2006) ${ }^{[25]}$ also reported sensory onset time of $9 \pm 5 \mathrm{~min}$ with isobaric bupivacaine as compared to $12 \pm 6$ min with isobaric levobupivacaine. 
Similarly when hyperbaric preparations of levobupivacaine and bupivacaine were compared by Alley et al (2002) ${ }^{[26]}$ they reported sensory onset of $18 \pm 6 \mathrm{~min} v / \mathrm{s} 15 \pm 9 \mathrm{~min} \mathrm{p}=0.30$ for levobupivacaine and bupivacaine respectively. Subasi et $\mathrm{al}^{[27]}$ reported onset time of $305 \pm 110 \mathrm{sec}$ with hyperbaric bupivacaine v/s $345 \pm 134 \mathrm{sec}$ with hyperbaric levobupivacaine, $p=0.279$. All these studies show comparatively faster onset with bupivacaine as compared to levobupivacaine.

In the present study Bromage score of 3 signifying complete motor blockage was achieved by both the agents, indicating comparable motor block. Previous all studies comparing levobupivacaine and bupivacaine ${ }^{[28],[29],[30],[31]}$ also reported that motor block by two agents are similar. Our study also confirmed that levobupivacaine and bupivacaine have a similar tolerability profile.

In our study incidence of hypotension and bradycardia was higher with hyperbaric bupivacaine, as compared with isobaric levobupivacaine which is mainly due to more cephalic spread of hyperbaric solutions.

Similarly previous studies when isobaric versus hyperbaric preparations of bupivacaine ${ }^{[8]}$ or levobupivacaine ${ }^{[14]}$ were compared incidence of hypotension and bradycardia was more with hyperbaric solution and it was attributed to hyperbaricity .It is well documented that hyperbaric solutions produce higher peak levels but may be associated with higher episodes of hypotension and bradycardia. ${ }^{[20]}$

Our study clearly shows that isobaric levobupivacaine in spinal anesthesia could be enrichment within the anesthetic arena and being less cardiotoxic it may be a reasonable alternative to racemic bupivacaine.

\section{Conclusion}

We conclude that isobaric levobupivacaine is a suitable alternative to hyperbaric bupivacaine in spinal anaesthesia for lower abdominal surgeries as it offers effective sensory motor blockage and stable hemodynamic profile. In addition this novel drug levobupivacaine may offer the advantage of significantly decreased cardiovascular and central nervous system toxicity.

\section{References}

1. Albright GA. Cardiac arrest following regional anesthesia with etidocaine or bupivacaine. Anesthesiology 1979; 51:2857

2. Marx GF. Cardio toxicity of local anesthetics: The plot thickens. Anesthesiology 1984; 60:3-5

3. Aberg G. Toxicological and local anesthetic effects of optically active isomers of two local anesthetic

4. Compounds. Acta Pharmacol Toxicol Scand 1972; 31:273- 86

5. Santos AC, De Armas PI. Systemic toxicity of levobupivacaine, bupivacaine and ropivacaine during continuous intravenous infusion to nonpregnant and pregnant ewes. Anesthesiology 2001; 95:1256-1264

6. Polley LS, Columb MO, Naughton NN, Wagner DS, van de ven CJM. Relative analgesic potencies of ropivacaine and bupivacaine for epidural analgesia in labor. Anesthesiology 1999; 90:944-50.

7. Lyons G, Columb M, Wilson RC, Johnson $\mathrm{RV}$. Epidural pain relief in labour: potencies of levobupivacaine and racemic bupivacaine. Br J Anaesth 1998; 81:899-901

8. Huang YF, Pryor ME, Mather LE, Verring BT. Cardiovascular and central nervous system effects of intravenous levobupivacaine and bupivacaine in sheep. Anesth Analg 1998; 46:245-9

9. Solakovic N. Comparison of Hemodynamic Effects of Hyperbaric and Isobaric Bupivacaine in Spinal Anaesthesia. Med Arh 2010; 64(1):11-14.

10. Fettes PDW, Hocking G, Peterson MK, Luck JF and Wildsmith JAW. Comparison of plain and hyperbaric solutions of ropivacaine for spinal anaesthesia.Br $\mathrm{J}$ Anaesth 2005; 94(1):107-11. 
11. Sanansilp V, Trivate T, Chomubai $P$, Visalyaputra S, Suksopee P, Permpolprasert L, Bormann BV. Clinical characteristics of spinal levobupivacaine: hyperbaric compared with isobaric solution. The Scientific World Journal 2012; volume 2012. Article id 169076, 7 pages. http://dx.doi.org/10.1100/2012/169076.

12. Dimarzio G, d'Elia A, Vessicchio L, Lettieri B. Comparison between isobaric levobupivacaine and hyperbaric bupivacaine in subarachnoid anesthesia for cesarean delivery: our experience. 5th international meeting- dialogues on anesthesia and intensive care (Napoli, 18-19 November 2011. Translational Medicine @ UniSa,ISSN 2239-9747. 2011, Special Issues 1 (2 Poster).

13. Gulen G, Gokhan C, Ayşe U, Fatih U, Cihangir B, Isin G, Adem B.A comparison of spinal anesthesia with levobupivacaine and hyperbaric bupivacaine for cesarean sections: A randomized trial. O J Anes 2012; 2: 84-89.

14. Vanna O, Chumsang L, Thongmee S. levobupivacaine and bupivacaine in spinal anesthesia for transurethral endoscopic surgery. J Med Assoc Thai 2006; 89: 11339.

15. D’Souza A.D, Saldanha N.M, Monterio A.D et al. comparison of bupivacaine, levobupivacaine and ropivacaine for lower abdominal surgeries 2013: Ijhsr Vol 4, Jan 2015

16. Morrison SG, Dominguez JJ and Frascarolo P. A comparison of the electrocardiographic cardiotoxic effects of racemic bupivacaine, levobupivacaine, in anesthetized swine. Anesth Analg 2000; 90:1308-1314.

17. Helmi M, Uyun Y, Suwondo B S and Widodo U. Comparison of Intrathecal Use of Isobaric and Hyperbaric Bupivacaine during Lower Abdomen Surgery. Journal of Anesthesiology Volume 2014, Article ID 141324, 4 pages.
18. Niemi L, Tuominen $M$, Pitkänen $M$ and Rosenberg $\mathrm{Ph}$. Effect of late posture change on the level of spinal anaesthesia with plain bupivacaine. Br J Anaesth 1993; 71(6): 807809

19. Vicent O, Litz R J, Hübler M and Koch T. Secondary cranial extension after spinal anesthesia with isobaric $0.5 \%$ bupivacaine following postural change. Anaesthesist 2003; 52(11):1035-1038.

20. Lui ACp, Polis TZ and Cicutti NJ. Densities of cerebrospinal fluid and spinal anaesthetic solutions in surgical patients at body temperature. Canadian Journal of Anaesthesia 1998; 45(4):297-303.

21. Gori F, Corradetti F, Cerotto V and Peduto VA.Influence of Positioning on Plain Levobupivacaine Spinal Anesthesia in Cesarean Section. Anesthesiology Research and Practice. Volume 2010, Article ID 212696, 4 pages

22. Lacassie HJ, Columb MO, Lacassie HP and Lantadilla RA. The relative motor blocking potencies of epidural bupivacaine and ropivacaine in labor. Anesth Analg 2002 Jul; 95(1):204-8,

23. Camorica M, Capogna G, Lyons G, Columb MO. Epidural test dose with levobupivacaine and ropivacaine determination of ED50 motor block after spinal administeration. Br J Anaesth 2004; 92:850-3.

24. Camorica M, Capogna G, Berritta C, Columb MO.The relative potencies for motor block after intrathecal ropivacaine, levobupivacaine, and bupivacaine. Anesth Analg. 2007 Apr; 104(4):904-7.

25. Vellosillo MDR, Garcia-Medina JJ, Cotaina AA, Pinazo-Duran MD, and BarberaAlacreu M. Spinal anesthesia for knee arthroscopy using isobaric bupivacaine and levobupivacaine: anesthetic and neuroophthalmological assessment. BioMed Research International, Volume 2014, Article ID 349034, 7 pages 
26. Fattorini F, Ricci Z, Rocco A, Romano R, Pascarella M A, Pinto G. Levobupivacaine versus racemic bupivacaine for spinal anesthesia in orthopaedic major surgery. Minerva Anesthesiol 2006; 72:637-44.

27. Chattopadhyay S, Halder S1, Saha GC, Karmakar S, Pahari S. Comparison of two concentrations of isobaric intrathecal levobupivacaine for vaginal hysterectomy. Indian J Pain 2013; 27(3):154-158.

28. Subaşı D, Ekİncİ O, Kuplay Y, Müftüoğlu T and Terzİoğlu B. Comparison of intrathecal hyperbaric bupivacaine and levobupivacaine with fentanyl for caesarean section. Göztepe T1p Dergisi 2012; 27(1):22-29.

29. Burke D, Kennedy S, Bannister J. Spinal anesthesia with $0.5 \%$ S (-) -Bupivacaine for elective lower limb surgery. Reg Anesth Pain Med 1999; 21:519-23

30. Turkmen A, Molralar DG, Ali A, Altan A. Comparison of the anesthetic effects of intrathecal levobupivacaine fentanyl and bupivacaine + fentanyl during caesarean section. Middle East J Anesthesiol 2012; 21:577-582 30. Cuvas O, Basar H, Yeygel A, Turkyilmaz E, Sunay MM. Spinal anesthesia for transurethral resection operations: levobupivacaine with or without fentanyl. Middle East J Anesthesiol 2010; 20:547 -552.

31. Mantouvalou M, Ralli S, Arnaoutoglou H, Tziris G, Papadopoulos G. Spinal anesthesia: Comparison of plain ropivacaine, bupivacaine and levobupivacaine for lower abdominal surgery. Acta Anaesth Belg 2008; 59:65-71. 